\title{
HIP INSTABILITY IN PATIENTS WITH MYELOMENINGOCELE
}

\author{
J. Rueda and N. C. Carroll, Toronto, Ontario, Canada \\ From the Department of Orthopaedic Surgery, the Hospital for Sick Children, Toronto
}

About a third of the children born with spina bifida have instability or deformity of the hips (Sharrard 1964b, Menelaus 1969). Paralysis of the abductors and extensors, with active power in the flexors and adductors, produces muscle imbalance and consequent subluxation or dislocation or other deformity of the hip. The muscle imbalance commonly produces flexion, adduction and lateral rotation deformities of the hip. Some of the secondary results are coxa valga, laxity of the capsule of the joint and increased anteversion. The pull of the iliopsoas moves the head of the femur upwards and backwards in such a way that the alignment of the neck approaches that of the diaphysis (Brookes and Wardle 1962). The lesser trochanter adopts a more anterior position. Associated with the changes in the femoral neck there is faulty acetabular development. Dislocation of the hip may be accompanied by pelvic and spinal deformities.

Surgical treatment of paralytic hip instability has been directed towards the correction of muscle imbalance and the correction of the secondary deformities in the neck of the femur, the joint capsule and the acetabulum. Watson-Jones (1926) discussed the mechanism of flexion-adduction deformity in paralytic dislocation of the hip and concluded that the adduction deformity was the more important. He discussed the importance of adequate adductor release in dealing with this problem and the difficulty of restoring muscle balance about the hip by tendon transfer.

Jones (1954) stated that coxa valga preceded dislocation and made it inevitable; the combination of structural instability of the hip and muscle weakness might make independent walking impossible. He described a technique of correcting the coxa valga by intertrochanteric osteotomy. Somerville (1959) made a distinction between true paralytic dislocation (due to muscle imbalance) and postural paralytic dislocation (due to pelvic obliquity). In both conditions there was "effective valgus" of the femoral neck. He stressed the value of also correcting rotation when the valgus deformity in true paralytic dislocation was corrected by osteotomy.

Transplant of the fascia lata to the erector spinae muscle in order to assist a weak or paralysed gluteus medius or maximus was described in 1927 by Hey Groves and by Ober. In 1950 Barr reported a significant number of cases in which this transplant was done with the principal aim of removing a deforming force. Hogshead and Ponseti (1964) reported the results of this operation in twenty patients with flexion contracture of the hip, nine of whom had myelomeningocele. They found the procedure effective in correcting the flexion deformity and in lessening the lumbar lordosis. They noted that hip instability was improved.

Mustard (1952) described the technique of iliopsoas tendon transfer designed to increase abductor power and stability of the hip in children with paralysis of the abductor muscles. He advised that varus osteotomy of the neck of the femur should precede tendon transfer in paralytic dislocation. Cruess and Turner (1970) reported the results of the Mustard operation in eleven patients with paralysis of the hip abductor muscles from spina bifida. They concluded that in the presence of pre-operative subluxation or dislocation, iliopsoas tendon transfer alone was not effective in restoring stability.

Sharrard (1959) described the technique of posterior iliopsoas tendon transfer. He found that the operation as described by Mustard failed to prevent recurrent dislocation when there was complete paralysis of the glutei medius, minimus and maximus. The early results of this procedure were reported in 1964 and a longer follow-up was reported by Carroll and Sharrard 
in 1972. Menelaus (1969) concluded that in children with dislocation and deformity of the hip from spina bifida, posterior iliopsoas tendon transfer ensured that the hip remained reduced, lessened the need for calipers, and prevented flexion deformity. He reduced the age for reduction and tendon transfer to eight months. If there was not a sufficiently strong iliopsoas to be transferred, he advocated varus and rotation osteotomy. Răliš (1970) found that the obturator externus was less atrophied than the other lateral rotator muscles in patients with myelomeningocele. Consequently, it played an important part in the cause of the lateral rotation deformity. Division of the obturator externus had to be considered when release was done for flexion, adduction and lateral rotation deformity.

\section{MATERIAL}

The twenty-one patients reviewed attend the spina bifida orthotic clinic at the Ontario Crippled Children's Centre. There were six boys and fifteen girls. Thirty iliopsoas tendon transfers had been performed on the hips of these children to correct deformity and provide

TABLE I

Ages of Patients with Hips Treated
By ILIOPSOAS Transfer
\begin{tabular}{|c|c|}
\hline $\begin{array}{c}\text { Age } \\
\text { (years) }\end{array}$ & Number of hips \\
\hline$\frac{1}{2}-1$ & 1 \\
$1-2$ & 5 \\
$2-3$ & 5 \\
$3-5$ & 17 \\
$5-7$ & 1 \\
$7-10$ & 1 \\
\hline
\end{tabular}

better hip stability. Fifteen iliopsoas tendon transfers were done by the Mustard technique and fifteen by the Sharrard technique. Review was from one to eight years after the iliopsoas transfer, with an average of three and a half years. The age of the children at the time of the iliopsoas tendon transfer varied between nine months and seven years with an age distribution as shown in Table I.

In addition to iliopsoas tendon transfers the following procedures were done: adductor tenotomy in eighteen patients, acetabuloplasty in one, innominate osteotomy in six, capsulorrhaphy in seven, open reduction in eight, closed reductions in five, intertrochanteric osteotomy in five, psoas division in two, and major soft-tissue release in one.

\section{METHODS}

At review each child was examined in detail and the findings were recorded on a special chart. In each hip a level of neurological function was assigned, based on the lowest root level of active muscle innervation (Sharrard 1964b). Range of motion, muscle power, walking aids required, and deformity of the spine were all recorded. Radiographs of the hips and photographs of the children in their braces were taken. Radiographs taken at the time of the review were compared with those taken before operation. The hips were classified as normal, dysplastic, subluxated or dislocated.

The term "dysplastic" was defined as meaning a hip which was in joint but in which there was some abnormality in the configuration of the acetabulum, femoral head or femoral neck 


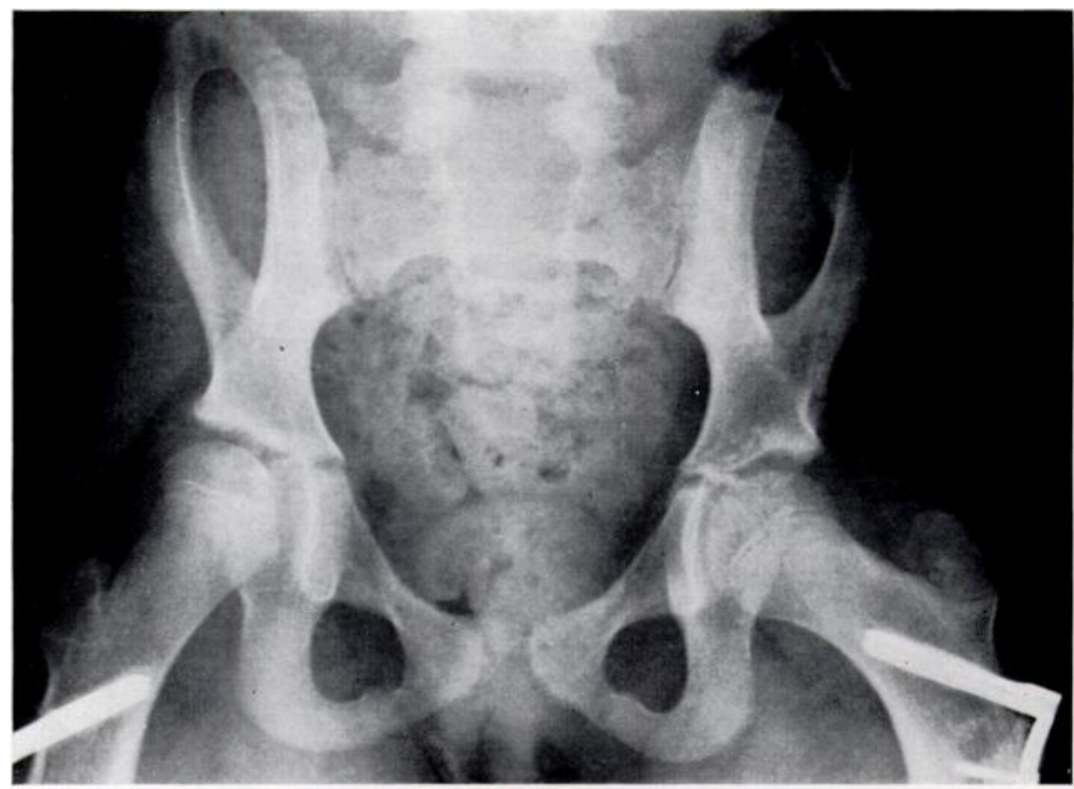

FIG. 1

Nine-year-old girl treated four years previously by subtrochanteric osteotomy and iliopsoas transfer (Sharrard technique). Radiograph showing dysplastic right hip, normal left hip.

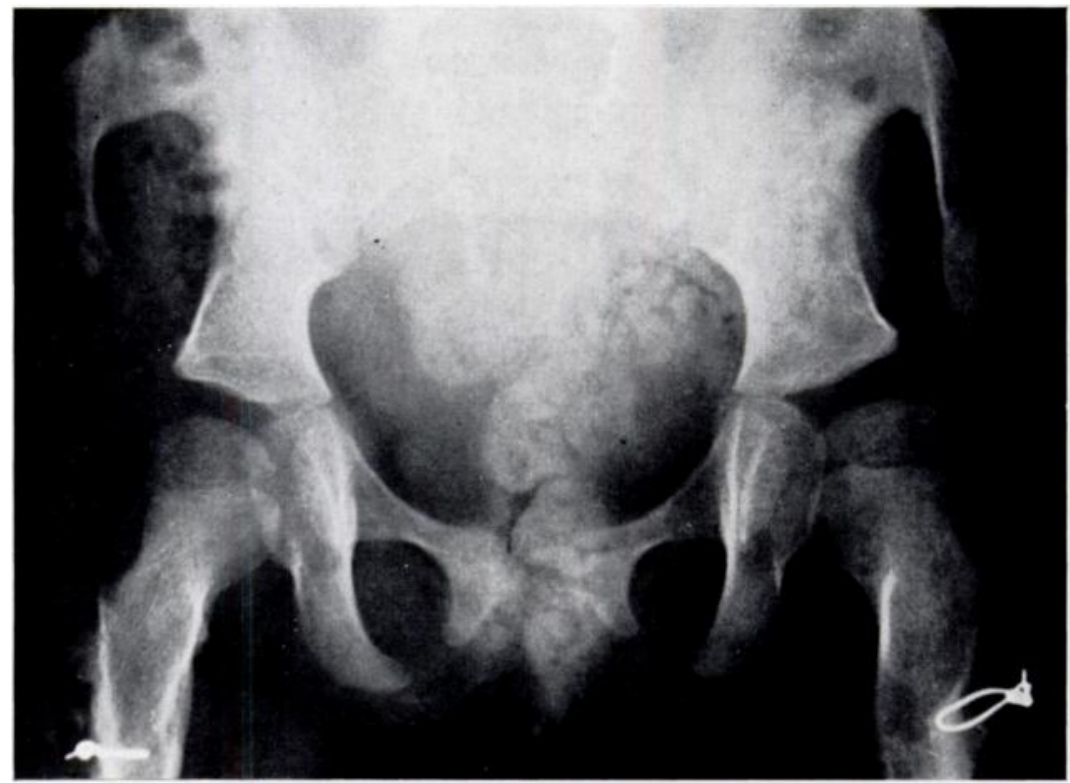

Fig. 2

Four-year-old girl. Iliopsoas tendon transfer (Mustard technique). Radiograph showing dysplasia of both hips. 


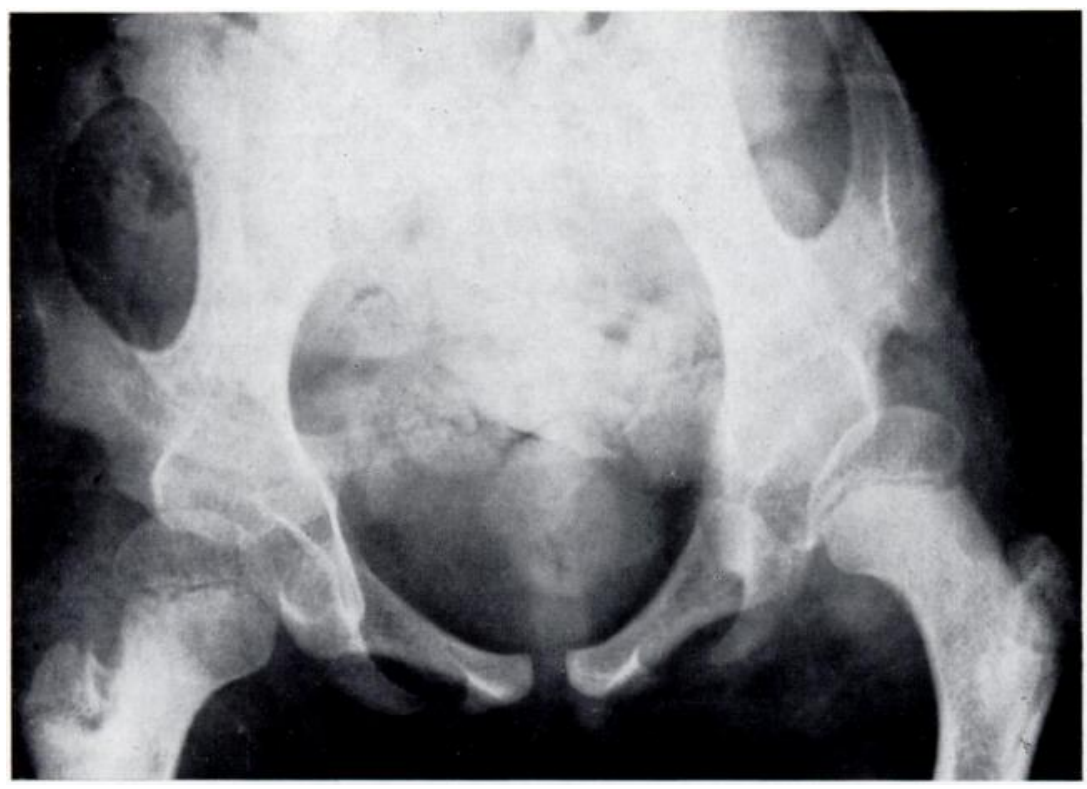

Fig. 3

Girl aged 4 years, four years after bilateral iliopsoas tendon transfer (Sharrard technique). Radiograph showing subluxation of both hips.

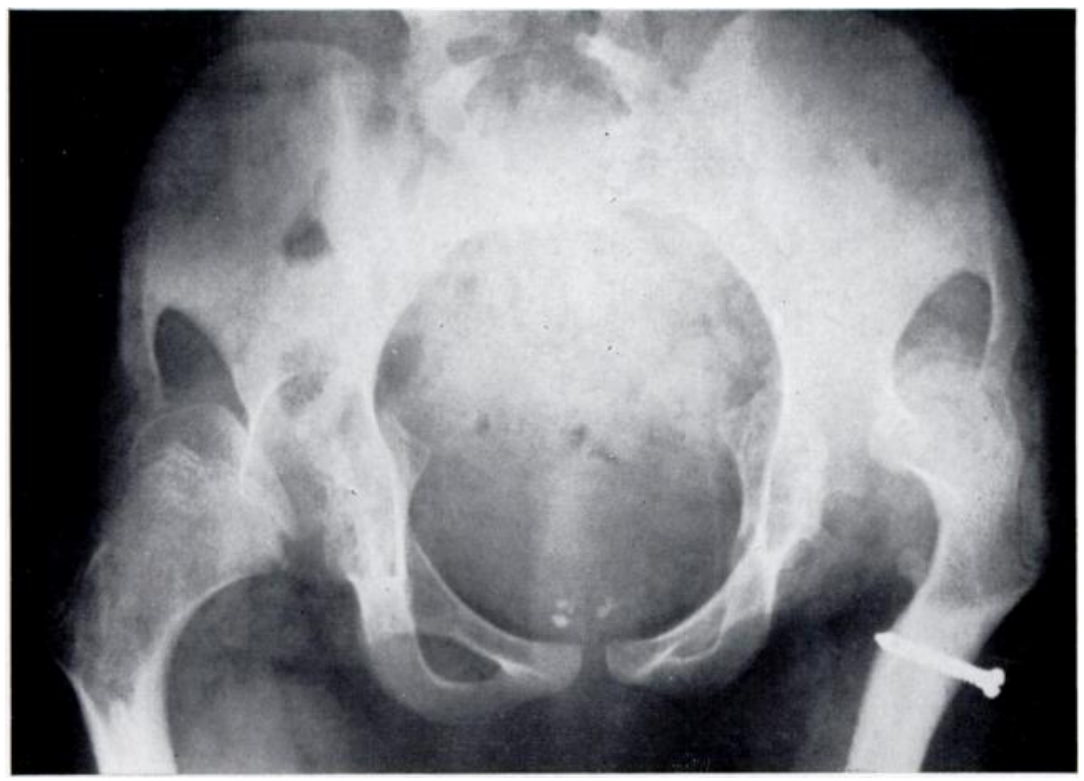

Fig. 4

Boy aged $11 \frac{1}{2}$ years, seven years after iliopsoas tendon transfer (Mustard technique). Radiograph showing dislocation of both hips.

vol. 54 B, NO. 3, AUGUST 1972 
(Figs. 1 to 4). For simplicity, muscle power was graded as nil; weak, active but not powerful enough to overcome gravity; and strong, able to overcome gravity.

In order to assess the effect of iliopsoas tendon transfer on abduction, all the hips with affection at the fifth lumbar level and below were excluded.

The walking aids required by patients with various levels of neurological function were recorded. A reciprocating gait brace is a brace with a back panel that has a gear box which enables the flexors of one hip to extend the opposite hip. A parapodium is an orthotic device designed for a patient with total paraplegia. It supports the spine while the patient is standing or sitting and enables independent standing without crutches.

TABLE II

ILIOPSOAS TRANSFER

Level of Neurological Function

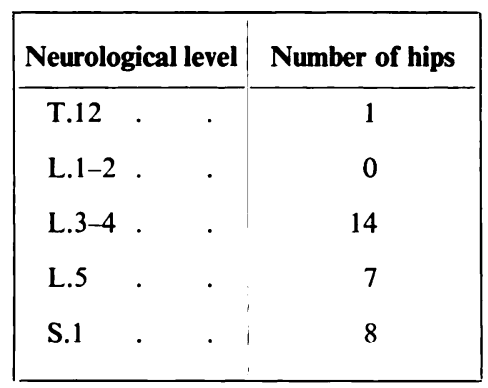

TABLE III

Level of Neurological function and Radiographic Appearance

\begin{tabular}{|c|c|c|c|c|c|}
\hline \multirow{3}{*}{\multicolumn{2}{|c|}{ Level of function }} & \multicolumn{4}{|c|}{ Classification } \\
\hline & & Normal & Dysplastic & Subluxated & Dislocated \\
\hline & & \multicolumn{4}{|c|}{ Number of hips } \\
\hline \multicolumn{6}{|c|}{ Before operation } \\
\hline T.12 & . & & & & 1 \\
\hline L. $3-4$ & . & & 2 & 7 & 5 \\
\hline L. 5 . & . & & 1 & 6 & \\
\hline S.1. & . & & 1 & 4 & 3 \\
\hline \multicolumn{6}{|c|}{ At review } \\
\hline $\mathrm{T} .12$ & . & & 1 & & \\
\hline L. 3-4 & . & 1 & 2 & 7 & 4 \\
\hline L.5. & . & & 1 & 6 & \\
\hline S.1 . & . & 1 & 4 & 1 & 2 \\
\hline
\end{tabular}

RESULTS

The neurological level of function of thirty hips is recorded in Table II. Table III relates the level of neurological function to the radiographic appearance of the hips before operation and at review. The hip with affection* at the twelfth thoracic level was dislocated before operation and was dysplastic at review. Five of the hips with affection at the third and fourth

* Throughout this paper "affected at" implies that there is no function below the level stated. 
lumbar levels were improved, eight were the same and one was worse. At review, the condition of the hips with affection at the fifth lumbar level was the same as it was before operation, whereas of the hips affected at the first sacral level, five were better and three remained unchanged.

A Mustard procedure had been done on five of the hips showing radiographic improvement and a Sharrard procedure on the other five. All these hips required other surgical procedures in addition to the tendon transfer.

Ten of the thirty hips were stable at the time of review. A Sharrard procedure had been done on six and a Mustard procedure on four. Seven of these hips were initially unstable. In two only a Mustard transfer was done; in two a Sharrard iliopsoas tendon transfer and a subtrochanteric osteotomy; in one a Mustard iliopsoas tendon transfer and a capsulorrhaphy; in one a Mustard tendon transfer, a capsulorrhaphy and an innominate osteotomy; and in the remaining hip a Sharrard procedure and an open adductor tenotomy.

Function: Range of motion-One hip was rigid. All the remaining twenty-nine hips had more than 90 degrees of flexion. Five hips had 60 degrees of abduction, fourteen had between 30 and 60 degrees, ten had less than 30 degrees, and one had a fixed adduction contracture.

In six hips there was a flexion contracture of less than 30 degrees. In fourteen hips there was a flexion contracture of between 30 and 45 degrees, and in six hips flexion contracture of more than 45 degrees. Ten of the hips with a moderate to severe flexion contracture had had a Mustard iliopsoas tendon transfer, and ten had had a Sharrard iliopsoas tendon transfer. The flexion deformity at the time of review was the same as that recorded before operation in twenty-one hips. It was improved in four and worse in five.

The rotational deformity was not a common problem in this group of hips. One had a medial rotation deformity and two hips had a lateral rotation deformity.

Motor power-The hips with affection at the twelfth thoracic level and the one rigid hip were excluded, leaving twenty-eight hips affected at the third, fourth and fifth lumbar and the first sacral levels. All these hips had strong flexors before operation, and at the time of review twenty-two still had strong hip flexors, indicating that even when the iliopsoas tendon was transferred there was enough power in the sartorius, pectineus and rectus femoris to flex the hip against gravity. At the time of review, twenty-one hips had strong adductors.

Excluding the hips affected at L.5 and S.1, we found no power of abduction in nine of thirty hips. There was weak power of abduction in five and power to abduct against gravity in one. This particular hip was subluxated.

When hips affected at the first sacral level were excluded only one hip could be held against gravity. Correlation between the neurological level of function and the aids required is poor, as for some children independent standing without crutches was preferable to a four point gait (Table IV). Six of the ten stable hips did not require bracing. All but one of the children fitted with braces could walk.

TABLE IV

GAIT AND BRACES

\begin{tabular}{|c|c|c|c|c|c|c|c|c|c|c|c|c|c|c|c|c|}
\hline \multirow{2}{*}{$\begin{array}{c}\text { Neurological } \\
\text { level }\end{array}$} & \multicolumn{2}{|c|}{ No aid } & \multicolumn{2}{|c|}{ Crutches } & \multicolumn{2}{|c|}{$\underset{\text { brace }}{\mathbf{B} / \mathbf{K}}$} & \multicolumn{2}{|c|}{$\begin{array}{c}\text { Long leg } \\
\text { brace }\end{array}$} & \multicolumn{2}{|c|}{$\begin{array}{c}\text { Reciprocating } \\
\text { brace }\end{array}$} & \multicolumn{2}{|c|}{ Parapodium } & \multicolumn{2}{|c|}{$\begin{array}{l}\text { Brace for } \\
\text { paraplegic }\end{array}$} & \multicolumn{2}{|c|}{ Sitting } \\
\hline & $\mathbf{S}$ & $\mathbf{U}$ & $\mathbf{S}$ & $\mathbf{U}$ & $\mathbf{S}$ & $\mathbf{U}$ & $\mathbf{S}$ & $\mathbf{U}$ & $\mathbf{S}$ & $\mathbf{U}$ & $\mathbf{S}$ & $\mathbf{U}$ & $\mathbf{S}$ & $\mathbf{U}$ & $\mathbf{S}$ & $\mathbf{U}$ \\
\hline T.12 & & & & & & & & & & & 1 & & & & & \\
\hline L. 3-4 & & & & 1 & 1 & & 1 & 3 & & 3 & & 1 & 1 & 2 & & 1 \\
\hline L. 5 & & & & & 1 & 1 & & & & 5 & & & & & & \\
\hline S.1 & 2 & & & & 1 & & & & & & & 2 & 2 & 1 & & \\
\hline
\end{tabular}

$\mathbf{S}=$ stable. $\mathbf{U}=$ unstable

Vol. 54 B, No. 3, AUGUST 1972 
Deformity of the spine was associated with hip instability in half of the patients, nine had scoliosis, four lordosis, one kyphoscoliosis and one kyphosis. Eight patients had pelvic obliquity, mild in six and moderately severe in two. In the patients with pelvic obliquity and

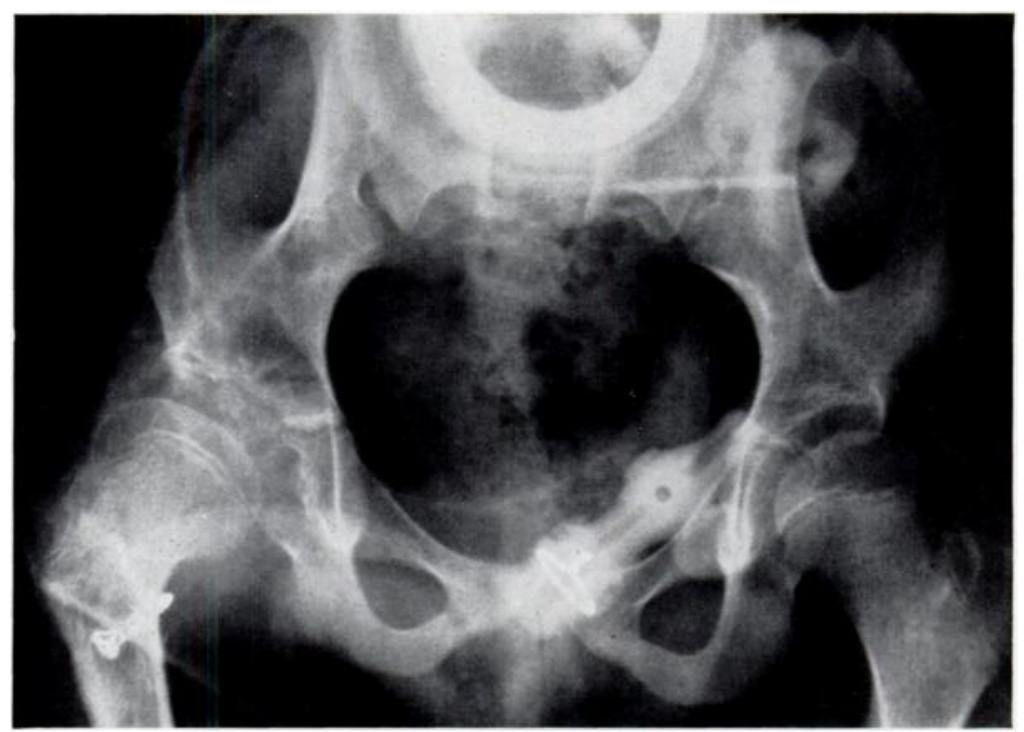

FiG. 5

Child aged 10 years, five years after adductor tenotomy right hip, open reduction, innominate osteotomy and transfer of iliopsoas tendon (Sharrard technique) The radiograph shows avascular necrosis of the right femoral head.

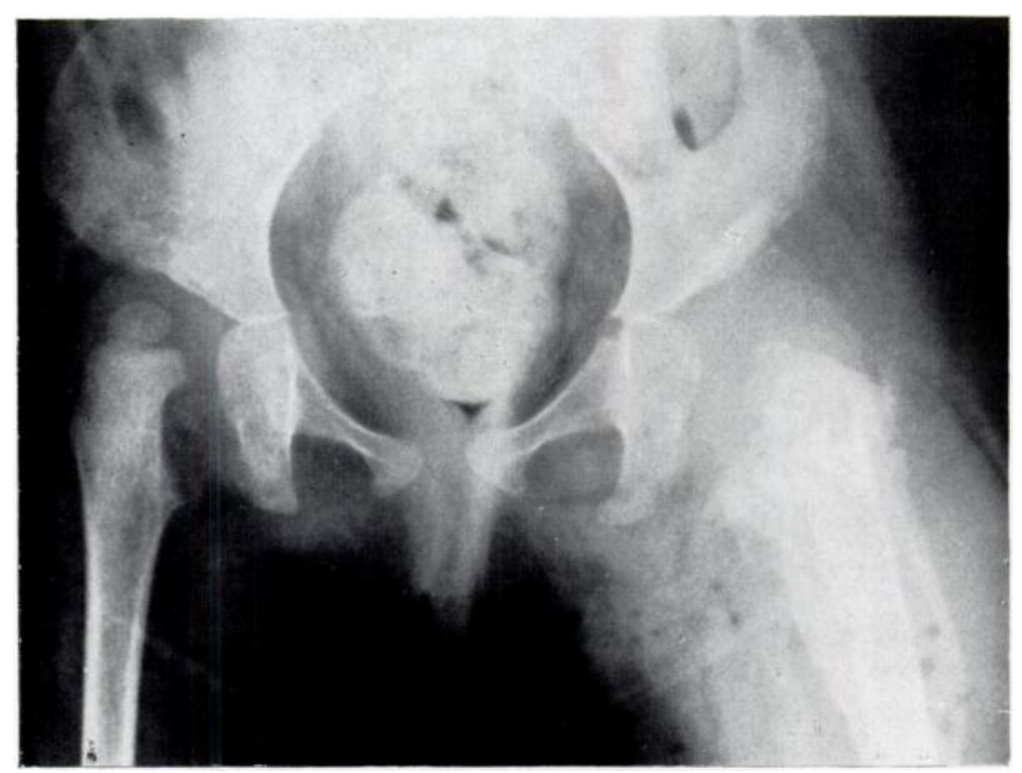

FIG. 6

Girl aged 7 years. Radiograph showing fracture of the neck of the left femur.

a symmetrical neurosegmental level of involvement, hip instability was more marked on the high side of the pelvis.

Complications of operation-No infections were reported. Avascular necrosis developed in three hips (Fig. 5). The incidence of pathological fracture was 20 per cent (Fig. 6). 


\section{DISCUSSION}

Hip instability in patients with myelomeningocele provides one of the more difficult problems in management. The incidence of hip instability and the results of treatment vary with the level of neurological affection. From our work in the spina bifida orthotic clinic at the Ontario Crippled Children's Centre, we know that a child born with a myelomeningocele will be capable of a swing-to or a swing-through gait in an orthotic device if he is intelligent, if his hydrocephalus has been controlled, if he has good head balance and if he has good power in the upper limbs. Before he can use an orthotic device the myelomeningocele must be resected and the defect covered with good skin. The spine must be well balanced, the feet plantigrade and the lower limbs free from severe contractures.

In which patients with myelomeningocele should one strive to maintain hip stability? Logically, in patients who are going to walk without braces above hip level. Theoretically, patients who have innervation down to the fourth or fifth lumbar level or below should be capable of walking with an orthotic device less extensive than a paraplegic brace. If it is important to have a stable hip only in those patients who are capable of walking without a paraplegic brace, then operation to produce stability is indicated only in patients with involvement below the fourth lumbar, fifth lumbar or the first sacral levels. The operation should be designed to restore muscle balance, and to correct any accompanying defects such as coxa valga, femoral anteversion, capsular laxity or deficient acetabulum. Operation is useless unless it improves limb function.

From this review it is clear that hip stability was only slightly improved by operation when the level of affection was the third, fourth or fifth lumbar segments. If it reached the first sacral level, stability was improved in more than half the hips. We were surprised to find that seven of the eight hips with a first sacral neurological level were unstable before operation. This finding is contrary to those of Sharrard (1964a and $b$ ) and Carroll and Sharrard (1972). The explanation must be that even though there was some power in the lateral hamstrings and gluteus maximus, it was not sufficient to balance the very strong hip flexors and adductors.

There are a number of possible causes of failure to achieve hip stability. One is delay in treatment. Most of the children in this series were operated on between the ages of three and five years. The longer the muscle imbalance persists the greater the secondary changes will become, and therefore the more difficult to correct. At review, most of the children with unstable hips had strong adductors. Since an iliopsoas tendon transfer is unlikely to provide strong hip abductors, an adequate open adductor tenotomy is essential before iliopsoas transfer. Another cause of failure is spasticity. One of the children with myelomeningocele also had an unrecognised diastematomyelia with a mixed upper and lower motor neurone lesion. Dislocation of the hip recurred after open reduction and iliopsoas tendon transfer. At the time of review she could not tolerate a brace and had difficulty in sitting. She has since had a further muscle release and resection of the head and neck of the femur to enable the limb to be positioned for sitting. Finally, in most of the unstable hips there was persisting coxa valga.

In this series, there was only one hip with a neurological level of function above the fifth lumbar segment that could be abducted against gravity after iliopsoas tendon transfer, and there was only one hip with a neurological level of function above the first sacral segment that could be extended against gravity. This child had had a Sharrard iliopsoas tendon transfer.

In the twenty-two children under review, there was no correlation between the neurological level of function and the type of orthotic appliance required. Some of the children managed better in a device that enabled them to stand without crutches; such a device, of course, necessitates bracing above hip level. Also, some of the children will progress to the point where less bracing is required.

A final and important question is: how should patients with similar problems be treated? Surely surgical treatment must be adapted to the individual needs of each patient. A child with a high level of neurological affection-for example, the twelfth thoracic or first or second

VOL. 54 B, NO. 3, AUGUST 1972 
lumbar level-will require bracing above hip level. In such a child, one should perhaps forget the radiographic appearance of the hip and confine operation to division of soft tissues to prevent deformities which would interfere with the child's using a brace. If, however, the child will be able to walk with less bracing than that required by a paraplegic an attempt should be made to ensure hip stability. The adductors will have to be weakened to permit adequate abduction. Often this can only be achieved by open adductor release. Whether or not the psoas should be transferred has not been answered by this review. The transferred iliopsoas is unlikely to provide significant active abduction or extension power. It may, however, have a beneficial function as a tenodesis. It seems reasonable to correct coxa valga and to plicate a lax hip capsule as well as to attempt to correct a deficient acetabulum.

A suitable form that is internationally acceptable and can be handled by the computer should be developed for prospective studies. On such a for $m$ the neurological level of function, the ranges of movement of the joints, any deformities, and the presence or absence of spasticity would be recorded. Such a development would facilitate statistical comparison of the results of treatment at various orthopaedic centres.

\section{SUMMARY}

1. The problem of paralytic hip instability has been studied in a series of twenty-one patients brought to a spina bifida clinic.

2. Thirty iliopsoas tendon transfers were done in an attempt to reduce deformity and improve hip stability.

3. At the time of review, ten of these hips were stable and twenty were unstable. Ten hips were improved by operation, and one hip was worse. The other nineteen remained the same. 4. All of the children except one were capable of walking with an orthotic device.

5. Some of the complexities of the problem of paralytic hip instability in the patient with myelomeningocele are discussed.

\section{REFERENCES}

BARR, J. S. (1950): Poliomyelitic Hip Deformity and the Erector Spinae Transplant. Journal of the American Medical Association, 144, 813.

Blundell Jones, G. (1954): Paralytic Dislocation of the Hip. Journal of Bone and Joint Surgery, 36-B, 375.

Brookes, M., and Wardee, E. N. (1962): Muscle Action and the Shape of the Femur. Journal of Bone and Joint Surgery, 44-B, 398.

Carroll, N. C., and Sharrard, W. J. W. (1972): Long-term Follow-up of Posterior lliopsoas Transplantation for Paralytic Dislocation of the Hip. Journal of Bone and Joint Surgery, 54-A, 551.

Cruess, R. L., and Turner, N. S. (1970): Paralysis of Hip Abductor Muscles in Spina Bifida. Journal of Bone and Joint Surgery, 52-A, 1364.

Ellison NaSh, D. F. (1956): Congenital Spinal Palsy. British Medical Journal, 2, 1333.

Fleming, J. L. (1957): Iliopsoas Transplant-Femoral Osteotomy for Paralytic Dislocation. Journal of Bone and Joint Surgery, 39-A, 697.

Groves, E. W. Hey (1927): Some Contributions to the Reconstructive Surgery of the Hip. British Journal of Surgery, 14, 486.

Hayes, J. T., Gross, H. P., and Dow, S. (1964): Surgery for Paralytic Defects Secondary to Myelomeningocele and Myelodysplasia. Journal of Bone and Joint Surgery, 46-A, 1577.

Hogshead, H. P., and Ponseti, I. V. (1964): Fascia Lata Transfer to the Erector Spinae for the Treatment of Flexion-Abduction Contractures of the Hip in Patients with Poliomyelitis and Meningomyelocele. Journal of Bone and Joint Surgery, 46-A, 1389.

Jones, G. B. (1954): Paralytic Dislocation of Hip. Journal of Bone and Joint Surgery, 36-B, 375.

McKibin, B. (1968): The Action of the Iliopsoas Muscle in the Newborn. Journal of Bone and Joint Surgery, 50-B, 161.

Menelaus, M. B. (1969): Dislocation and Deformity of the Hip in Children with Spina Bifida Cystica. Journal of Bone and Joint Surgery, 51-B, 238.

Menelaus, M. B. (1971): The Orthopaedic Management of Spina Bifida Cystica. Edinburgh and London: E. \& S. Livingstone. 
Mustard, W. T. (1952): Iliopsoas Transfer for Weakness of the Hip Abductors. Journal of Bone and Joint Surgery, 34-A, 647.

MUSTARD, W. T. (1959): A Follow-Up Study of Iliopsoas Transfer for Hip Instability. Journal of Bone and Joint Surgery, 41-B, 289.

NiCOD, L. (1969): Luxation de la hanche chez les myéloméningocèles. Annales de chirurgie infantile, 10, 121.

Ober, F. R. (1927): An Operation for the Relief of Paralysis of the Gluteus Maximus Muscle. Journal of the American Medical Association, 88, 1063.

RÁLIš, Z. (1970): Muscle Morphology in Spina Bifida; Hip Deformities. Developmental Medicine and Child Neurology, 12, Supp. 22, 137.

Salter, R. B. (1969): An Operative Treatment for Congenital Dislocation and Subluxation of the Hip in the Older Child. In Recent Advances in Orthopaedics. Chapter 10, p. 325. Edited by A. G. Apley. London: J. \& A. Churchill Ltd.

Sharrard, W. J. W. (1959): Congenital Paralytic Dislocation of the Hip in Children with Myelomeningocele. Journal of Bone and Joint Surgery, 41-B, 622.

Sharrard, W. J. W. (1964a): The Segmental Innervation of the Lower Limb Muscles in Man. Annals of the Royal College of Surgeons of England, 35, 106.

Sharrard, W. J. W. (1964b): Posterior Iliopsoas Transplantation in the Treatment of Paralytic Dislocation of the Hip. Journal of Bone and Joint Surgery, 46-B, 426.

Sharrard, W. J. W. (1967): Paralytic Deformity in the Lower Limb. Journal of Bone and Joint Surgery, 49-B, 731.

Sharrard, W. J. W. (1969): The Orthopaedic Surgery of Cerebral Palsy and Spina Bifida. In Recent Advances in Orthopaedics. Chapter 8, p. 265. Edited by A. G. Apley. London: J. \& A. Churchill Ltd.

Somerville, E. W. (1959): Paralytic Dislocation of the Hip. Journal of Bone and Joint Surgery, 41-B, 279.

Taillard, W., Compère, J., Vasey, H., and Berney, J. (1969): L'orthopédie des spina bifida. Annales de chirurgie infantile, $10,87$.

WATSON-Jones, R. (1926): Spontaneous Dislocation of the Hip. British Journal of Surgery, 14, 36.

Weissman, S. L. (1959): Capsular Arthroplasty in Paralytic Dislocation of the Hip. Journal of Bone and Joint Surgery, 41-A, 429.

vol. 54 B, No. 3, AUGUST 1972 